\title{
The status of memory following experimentally induced amnesias: Gone, but not forgotten
}

\author{
DAVID C. RICCIO and RICK RICHARDSON \\ Kent State University, Kent, Ohio
}

Although the concept that information processing continues following the termination of a learning trial has long been represented in human research (e.g., "rehearsal"), it has only recently gained acknowledgement in studies of animal memory. An influential paper by McGaugh (1966) provided an important impetus in this direction by reviewing evidence that various posttrial manipulations could modulate retention. Thus, electroconvulsive shock (ECS) after training impaired memory, whereas strychnine administration enhanced it. Although McGaugh's (1966) specific interpretation was linked to a consolidation model of memory, the more general impact of his analysis may have been in calling attention to phenomena implying that the processing of information continues after the events constituting the nominal learning episode have ended.

The notion of postacquisition processing has come to furnish a frame of reference for a variety of studies of animal memory (e.g., directed forgettingMaki \& Hegvik, 1980, and Stonebraker \& Rilling, 1981; memory counterconditioning-Richardson, Riccio, Jamis, Skozcen, \& Cabosky, 1982; primingWagner, 1978; posttrial surprise-Wagner, Rudy, \& Whitlow, 1973), but our presentation here will concentrate on a phenomenon that has been particularly well established, namely, experimentally induced retrograde amnesia (RA). In this paper we consider some of the data that demonstrate that postacquisition traumatic insult can produce profound memory losses. But we will also suggest that these retrograde amnesias are not attributable to disruption or failure of the storage process. Rather, the memory loss appears to be linked to the lack of appropriate cues for retrieval. It is in this respect, then, that memory can

Preparation of this paper was supported in part by NIMH Grant MH 37535 to D.C.R. Portions of this material were presented at the Midwestern Psychological Association, Chicago, May 1984, as part of a symposium organized by Donald $R$. Meyer and entitled "Long-Term Memories: How Durable, and How Enduring?" The various contributions of many students, both present and past, is warmly acknowledged. As the present paper also illustrates, one's students can be "gone, but not forgotten." Requests for reprints may be sent to David Riccio, Department of Psychology, Kent State University, Kent, OH $\mathbf{4 4 2 4 2 .}$ be "gone, but not forgotten," a distinction obviously similar to Tulving's more incisive description that memory can be available but inaccessible (e.g., Tulving \& Pearlstone, 1966; Tulving \& Psotka, 1971).

\section{Historical Overview}

Some 35 years ago, Duncan (1949) reported that administration of ECS to rats following daily active avoidance training impaired acquisition of the avoidance behavior. Moreover, the effect was time-dependent: subjects receiving ECS at a short delay after each trial (e.g., 20, 40, or $60 \mathrm{sec}$ ) showed greater impairment than those given ECS after a longer interval (e.g., 1 or 4 hours). The findings captured the attention of many experimentalists and initiated what eventually became a new direction of animal research on memory processes. A major boost to this interest was undoubtedly provided by the publication, at about the same time, of Hebb's (1949) Organization of Behavior, with its relevant and influential speculation about reverberatory circuits.

Although Duncan interpreted his findings in terms of memory disruption, other investigators pointed out a potential problem. In the escape/avoidance task, subjects received ECS after entering the safe goalbox so that the temporal gradient could reflect the effect of punishment rather than memory loss. If the amnestic agent produced momentary painful stimulation before rendering subjects unconscious, then perhaps the subjects' failure to perform well (i.e., run rapidly to the goalbox) represented fear associated with the goalbox. Instead of a gradient of forgetting, the change in performance could simply indicate the well-known gradient of punishment. Duncan had attempted to address this argument by removing some subjects from the goalbox and giving them a footshock comparable in intensity to the ECS. Although the gradient for rats in this explicitly punished condition was much steeper than that for subjects given ECS, subjects receiving footshock after the short intervals did show a performance decrement. This outcome left open the possibility that punishment was the basis for the obtained temporal gradient. 
With the introduction of the so-called "passive avoidance" (punishment) task, however, the argument was soon settled in favor of a memory interpretation (e.g., Madsen \& McGaugh, 1961). In the passive avoidance paradigm, subjects receive inescapable aversive stimulation contingent upon some response (e.g., stepping from a ledge to the grid floor) and are subsequently tested for their tendency to refrain from making that response. Since retention controls typically show long-latency responses at testing, administration of the amnestic agent following the training trial should further increase response latency if the treatment is functioning as a second punisher. However, the nearly ubiquitous finding is that latencies are shorter in the amnestic group than in training-only controls. Thus, the fact that subjects receiving footshock punishment and amnestic treatment return more rapidly to the stimuli associated with footshock provides a compelling argument that some aspect of their training memory has been disrupted. The punishment task has another property, which has made it particularly attractive for amnesia studies: the fact that conditioning can be established in one trial, in contrast to tasks requiring multiple trials, permits at least nominal specification of when learning occurs. Thus, with a definitive operational marker of acquisition, the effects of delay of amnestic treatment on the severity of retention loss could be more precise and uncontaminated by partial learning from previous trials.

Despite the potential advantages of the passive avoidance procedure, the use of this technique in research on RA does not automatically insure that performance deficits reflect forgetting. The logic of the design, in which any aversive properties of the amnestic agent can summate with the training reinforcer, requires that the amnestic treatment be closest (temporally) to the stimuli paired with footshock. Thus, it is possible to subvert the procedure (and defeat the purpose) by permitting an escape response. In that case, adminstration of the amnestic treatment after a subject escapes to a safe area produces a situation in which one set of cues is associated with footshock, whereas another set of stimuli is contiguous (temporally) with amnestic exposure. If the latter relationship were to result in conditioned fear, then short latencies at testing could reflect either of two things: memory loss or fear-motivated escape from those stimuli paired with the amnestic agent-an interpretative dilemma we inadvertently generated (to our chagrin) in an early study (Riccio, Hodges, \& Randall, 1968). Although some studies still fail to indicate the type of response (escapable vs. inescapable) permitted during training, it seems clear that this procedural "detail" is not trivial.

Finally, a comment on the term "passive avoidance task" seems appropriate, because the label is now used to encompass a variety of procedures.
Mowrer (1960) appears to have introduced the term to indicate how the two-process theory of avoidance could account for the suppressive effects of punishment: If response-linked stimuli provide the fear CS, then cessation of responding, by removing these stimuli, is strengthened. While Mowrer's interpretation implied a specific contingency between responding and delivery of aversive stimulation during training, the term "passive avoidance" has come to be applied to any situation in which the test involves refraining from making a response, regardless of the particular type of training (instrumental punishment or Pavlovian fear conditioning).

A variety of studies using the passive avoidance paradigm have confirmed Duncan's finding that ECS impaired retention and that the deficit diminished as the interval between training and treatment lengthened. Because this functional relationship could not be attributed to noxious effects of the amnestic agent, the general paradigm quickly attracted interest as a potent way to examine psychobiological processes in memory. In addition to ECS, such diverse agents as $\mathrm{CO}_{2}$ (Paolino, Quartermain, \& Miller, 1966), Metrazol (Palfai \& Chillag, 1971), some anesthetics (Abt, Essman, \& Jarvik, 1961; Cherkin, 1969), electrical stimulation of portions of the limbic system (Kesner \& Doty, 1968; McDonough \& Kesner, 1971), and both decreased (Beitel \& Porter, 1968; Riccio, Hodges, \& Randall, 1968) and elevated (Mactutus, Ferek, \& Riccio, 1980; Misanin, Vonheyn, Bartelt, Boulden, \& Hinderliter, 1979) body temperatures were among the treatments shown to produce timedependent memory loss. Although many of these treatments are potent stressors, it seems unlikely that stress per se is responsible for RA. For example, in an attempt to halt putative rehearsal-like processes and thus reduce the vulnerability of memory to amnestic treatment ("deactivation"), Richardson, Riccio, and Molenda (1982) exposed rats to a highly traumatic and realistically life-threatening situation (LTS). However, no protection from amnesia was obtained when the LTS was followed by deep body cooling. Furthermore, the stressful LTS itself had no apparent influence on memory. Because the various agents effective in inducing RA also result in marked changes in neural activity of the CNS, this aspect of the amnestic treatment seems a more likely cause than stress effects for the memory loss; however, as will be seen, these changes do not impair retention by destroying the engram.

For a number of years, the prevailing interpretation of the memory deficit in retrograde amnesia has centered around interruption of consolidation of the memory trace. The electrophysiological evidence of seizure-like activity (e.g., spike discharges) in the brain produced by amnestic agents seemed the natural cause for storage impairment (Duncan, 1949; Glickman, 1961; McGaugh, 1966; Vardaris, Gaebelein, 
\& Riccio, 1973; Zornetzer \& McGaugh, 1971). Moreover, this interpretation jibed nicely with Hebb's notion that a learning episode initiated reverberatory neuronal activity in the brain. The reverberatory circuits established structural changes which later could facilitate synaptic transmission along the pathway, resulting in the conditioned response. By creating an electrical "storm," amnestic agents were thought to interrupt the reverberatory circuits, and thus prevent the full establishment of the engram. Clearly, this view accounted rather nicely for the temporal gradient of RA-the longer the amnestic agent is delayed, the greater the likelihood that storage is completed. With intermediate delays of treatment, partial consolidation occurs and is reflected in the intermediate level of performance at testing.

One implication of the storage disruption hypothesis is that retrograde amnesia represents a permanent, although not necessarily total, loss of memory. Although the information could presumably be reacquired (or, more precisely, acquired) through relearning, the status of memory after amnestic treatment seems straightforward: since retention loss is attributed to failure to store the target information, later recovery of memory is precluded. Although "shrinking" of RA in the human amnestic syndrome was known to occur, this was not taken as a serious theoretical problem. Reduction of the backward extent of amnesia could represent emergence of the partial memory which characterizes older information on the delay gradient, or, more artifactually, relearning about earlier events from various sources (conversations with friends, reading, etc.). The "consolidation interruptus" tenets were appealing to many investigators-and this lab was no exception (Riccio, Gaebelein, \& Cohen, 1968; Riccio, Hodges, \& Randall, 1968; Riccio \& Stikes, 1969; Vardaris et al., 1973).

\section{Findings Problematic for a Storage-Disruption View of Retrograde Amnesia}

Spontaneous recovery. As often seems to happen in research, a reasonably clear perspective soon began to cloud over as new questions were posed. For example, Zinkin and Miller (1967) reported that rats showed spontaneous recovery from ECS-induced RA when retested on Days 2 and 3. Clearly, memory that wasn't stored shouldn't recover. But, as was soon recognized, the spontaneous recovery observed by Zinkin and Miller may have been an artifact of their experimental design, in which the same subjects were tested at each of several intervals. With the repeated measures procedure, if RA were not complete, then any residual fear elicited on the first (short latency) re-entry response could serve as a conditioned punisher to increase the latency on subsequent test trials.
However, such changes in performance are more aptly described as new learning rather than memory recovery. Inasmuch as a number of experiments using a between-groups design to assess RA at different retention intervals have found little change in severity of memory loss (e.g., Herz \& Peeke, 1967, 1968; King \& Glasser, 1970; Luttges \& McGaugh, 1967; Riccio \& Stikes, 1969), the status of truly "spontaneous" recovery from amnesia appears doubtful. For what turned out to be the wrong reason, then, these initial findings of spontaneous recovery from RA hinted that the lack of memory in RA studies might not be tantamount to the eradication of the engram.

Repeated exposure to the amnestic episode. A second potential challenge to the view that the RA resulted from interrupted consolidation came from studies on the rapid reversal of RA in subjects exposed to repeated training/amnesia treatment episodes. That the Zeitgeist was operating is suggested by the fact that four independent studies on this topic appeared at roughly the same time (Kesner, McDonough, \& Doty, 1970; Nachman \& Meinecke, 1969; Pfingst \& King, 1969; Riccio \& Stikes, 1969). Although each used a different amnestic agent, and somewhat different procedures, all four investigations found what might be considered as surprisingly little evidence of RA "the second time around." For example, after finding no diminution in the severity of hypothermia-induced RA over a 10-day retention interval with a separate group design, it occurred to us (Riccio \& Stikes, 1969) that the behavioral expression of amnesia (short latencies to re-enter the shock compartment) could be exploited to determine the "repeatability" of amnesia for each subject. In a subject that displayed amnesia, punishment training could be repeated, followed again by hypothermia. If, as we naively assumed, the amnestic agent erased the slate and produced a tabula rasa (or nearly so), then subjects should be rendered amnestic again. Because amnesia might not be absolute, modest increments in memory strength would be expected over successive episodes. Five repetitions were planned, but we never got beyond the second treatment. Virtually every subject showed maximum performance on the second test, thus precluding further sessions (Riccio \& Stikes, 1969). Strong conclusions about total lack of amnesia are not warranted in this situation inasmuch as ceiling effects could have obscured weak amnesia (although the test session was $600 \mathrm{sec}$ ). Furthermore, the "scale" of memory provided by this simple go/no-go test may not permit additivity operations in which small amounts of amnesia summate to an intermediate level. Or it could be that slight residual memory may facilitate more rapid consolidation/storage of learning on the second trial and block amnesia. All these are plausible objec- 
tions, yet the abrupt transition from RA to retention still seemed puzzling.

\section{Further Problems for a Storage Failure Interpretation of RA}

Familiarization effects. Somewhat stronger but still indirect evidence against the view that amnesia represents "erasure" of memory comes from two other classes of studies: blocking of amnesia through familiarization (FAM) and the delayed onset of RA. In the familiarization paradigm originally described by Lewis, Miller, and Misanin (1968), exposure to the training apparatus prior to the training/ECS administration resulted in an attenuation of amnesia. The familiarization effect proved to be relatively stimulus specific, in that a generalization-like decrement in protection from amnesia occurred as the preexposure environment became increasingly different from the training situation (Miller, 1970). A particularly potent blockage of amnesia occurred when the preexposure consisted of an actual training trial followed by prolonged latent extinction (Jensen \& Riccio, 1970). Although there is relatively little systematic information on the persistence of FAM, Hinderliter and Riccio (1977) found that with the latent extinction procedure (Jensen \& Riccio, 1970) amnesia was attenuated even after a 15-day interval between preexposure and the training/hypothermia episode.

One retrieval-oriented interpretation of these findings is that amnesia was reduced because subjects "tagged" information about their environment during preexposure and the new information provided during subsequent introduction of the punishment contingency was assimilated into an already organized memory system (Lewis et al., 1968). While this "elaboration" hypothesis was designed to account for the environmental exposure modulation of amnesia, the "latent learning" aspect of the interpretation is not necessarily inconsistent with a storage model: with less new information to store, consolidation is achieved more rapidly (cf. Jensen \& Riccio, 1970). [In either case, these findings pose an interesting dilemma vis-à-vis another preexposure phenomenon, "latent inhibition." An extensive literature has developed around the finding in Pavlovian conditioning studies that exposure to the CS alone markedly impairs acquisition when the CS is subsequently paired with a UCS (Carlton \& Vogel, 1967; Channell \& Hall, 1983; Lubow \& Moore, 1959). Although this "latent inhibition" effect is now generally regarded as an attentional change or habituation effect rather than true "inhibition," there is little doubt that excitatory strength to the CS is reduced (Reiss \& Wagner, 1972; but see Kasprow, Cacheiro, Balaz, \& Miller, 1982, for an intriguing explanation of this phenomenon in terms of retrieval failure). But weaker learning would be expected to enhance the effect of an amnestic agent (i.e., produce more severe RA) rather than attenuate it (see Hall, 1980, for a discussion of a similar paradox with respect to several other learning phenomena).]

As Misanin and his colleagues have noted, an explanation of protection from amnesia based on prior learning about the environment is less applicable to data showing that noncontingent exposure to the UCS will also attenuate RA (Hinderliter, Smith, \& Misanin, 1973; cf. Jensen, Riccio, \& Gehres, 1975). Perhaps even more striking, however, is the attenuated amnesia that results from prior exposure to the amnestic agent itself. Hinderliter has demonstrated that administration of ECS (Hinderliter et al., 1973) or hypothermia (Hinderliter, 1978) reduces the later effectiveness of these treatments as amnestic agents, although, for hypothermia, more than a single preexposure is required. In an interesting extension of these findings, Kasprow, Schachtman, Balaz, and Miller (1983) showed a cross-agent familiarization effect: preexposure to cycloheximide attenuated ECSinduced RA and vice versa, suggesting an important commonality between these two treatments.

The fact that these and other types of prior experiences (e.g., David-Remacle, 1973) can dampen the severity of amnesia led us to recognize what appears to be an interesting paradox with respect to RA (Jensen et al., 1975; Riccio, 1975). On the one hand, amnesia is a robust phenomenon that has been readily obtained, not only in many different laboratories, but also with various learning tasks and experimental parameters, with a number of species, and with a variety of amnestic treatments. On the other hand, the amnesia can be partially or completely blocked by surprisingly simple or mundane types of proactive experiences. Perhaps subjects fail to differentiate training from treatment events as carefully as do experimenters. If so, preexposure manipulations that facilitate discriminations among the various components of the episode might alleviate amnesia by reducing the role of amnestic agents as a contextual state (see section on reversal of amnesia for elaboration).

Delayed Onset of RA. The second type of study providing indirect evidence that amnestic treatments do not "erase" memory are those tracking the development of forgetting after an amnestic treatment. Although we now know that amnesia often is not present immediately after traumatic insult, this outcome was not apparent for some time, since many of the studies on induced amnesia interpolated a 1-day interval between treatment and testing. The intent of this delay was to permit full recovery from any untoward side effects of the amnestic agent, and it was typically assumed that the outcome at $24 \mathrm{~h}$ represented what would be obtained at shorter intervals as well. 
However, it turns out that testing can reasonably be conducted after much shorter intervals without contamination by performance artifacts. When such testing has been done, amnesia is found not to develop until some minutes or even hours (Geller \& Jarvik, 1968; McGaugh \& Landfield, 1970; Miller \& Springer, 1971) after the ECS administration. This delayed onset of amnesia has been replicated and extended to hypothermia-induced RA (Hinderliter, Webster, \& Riccio, 1975; Mactutus \& Riccio, 1978). In the latter study, separate groups of rats were tested at $4,8,12$, or 16 h after hypothermia treatment. The development of RA was quite slow, with test scores remaining high for up to $12 \mathrm{~h}$, then declining rapidly.

This lack of amnesia shortly after traumatic insult has its counterpart in the natural world of memory events. Football players suffering a concussive injury demonstrated good recall of the preceding events when queried within $30 \mathrm{sec}$ after removal from the field; however, after several minutes recall had deteriorated drastically. The rather unusual "control" group (players suffering serious injuries to other parts of their bodies) showed no such decline in memory with delayed testing (Lynch \& Yarnell, 1973).

These various findings on delayed onset of RA do not, of course, indicate that memory is still available (if inaccessible) after the amnesia develops. Indeed, although the data would appear to pose problems for a consolidation view, it is possible to argue for a two-trace position in which long-term, but not short-term, memory processes are disrupted in RA (McGaugh \& Dawson, 1971). Nevertheless, since one might expect the disruptive effects of amnestic agents to be almost immediate, the results make it easier to believe that RA may be less a matter of interfering with storage of the engram and more a matter of what cues are available for retrieval.

\section{Direct Challenges to the Consolidation Interpretation of Amnesia}

RA for old memory. If an amnestic treatment disrupts establishment of the memory engram in a timedependent manner, then obtaining RA for old, wellconsolidated information would seem highly improbable. The well-replicated temporal gradient of amnesia reveals that within a relatively short time after training there is a point after which the amnestic treatment is essentially ineffective. Thus, there seems little reason to entertain the possibility that a still older memory might be influenced by an amnestic treatment. In accordance with the "law of regression" proposed by Ribot (1883) on the basis of his extensive clinical observations, older memories have been considered impervious to the same insult that produces profound loss for newer memories. Accordingly, as D. R. Meyer (1972) has noted, evidence of amnesia for old, well-consolidated informa- tion may seem somewhat startling and in some cases has been met with considerable skepticism.

Probably the first convincing demonstration of RA for old memory was obtained in a study by Misanin, Miller, and Lewis (1968; cf. Schneider \& Sherman, 1968 , for a related finding). In the Misanin et al. study, rats receiving ECS $24 \mathrm{~h}$ after condiditioned suppression training exhibited, as would be expected, no RA. But amnesia was obtained for a similar "old memory" group if reexposure to the fear cues $(\mathrm{CS}+)$ preceded ECS administration. The effect was not attributable to extinction, since the comparable cue-only exposure group showed merely a slight decline in test performance. This outcome is consistent with Lewis's (1979) view that it is the state of activity of memory, rather than its age, that determines whether the information will be susceptible to an amnestic treatment. Presumably, old memories are inactive, but exposure to some component of the original training situation (e.g., the fear cues) activates the earlier memory and allows subsequent administration of an amnestic agent to modify the memory.

Because some failures (e.g., Banker, Hunt, \& Pagano, 1969; Gold \& King, 1972), as well as successes (e.g., DeVietti \& Holliday, 1972; Gerson \& Hendersen, 1978), in attempting to replicate amnesia for old reactivated memory were reported, we have conducted several studies on this issue. The findings generally support the original observation of Misanin et al. (1968) and also indicate some intriguing points of comparison between amnesia for newly acquired memories and amnesia for old (reactivated) memory. In an initial experiment, rats that had received onetrial punishment training $24 \mathrm{~h}$ previously were given a 30-sec nonreinforced exposure to the shock compartment. Whether this cue exposure was followed by either deep or mild reductions in body temperature, subsequent retention was significantly impaired relative to noncooled groups receiving either handling or cue exposure (Mactutus, Riccio, \& Ferek, 1979). The effectiveness of mild hypothermia in producing RA was somewhat surprising because no memory impairment had been seen when this treatment was administered after new learning (Riccio, Hodges, \& Randall, 1968). A second experiment in this study replicated this effect and directly confirmed that severity of hypothermia treatment interacted with the age of memory in producing RA. Thus, old memory, when reactivated by cue exposure, became vulnerable to both a mild and a severe amnestic treatment, whereas a newly acquired memory was susceptible to only the severe treatment.

Subsequently, we (Mactutus, Ferek, George, \& Riccio, 1982) suggested that the unanticipated outcome of greater vulnerability of reactivated memory could provide an interpretation of an otherwise perplexing aspect of several studies by Meyer and his 
colleagues (Howard, Glendenning, \& D. R. Meyer, 1974; Howard \& D. R. Meyer, 1971; Robbins \& D. R. Meyer, 1970). Using a series of three discrimination problems, these investigators showed that ECS following the final problem would produce amnesia for an earlier discrimination that was learned under the same motivational conditions. Thus, if the first and third problems were shock motivated and the second was food motivated, administration of ECS after mastery of the third task disrupted retention of the first but not the second discrimination. Since the shock provided a common motivational state for two tasks, that outcome is consistent with other evidence of amnesia for old reactivated memory. But what has been puzzling is that the most recent learning was not disrupted by the ECS. Mactutus et al. (1982) proposed that perhaps the early task was subject to disruption by an agent not quite severe enough to impair the new habit, an outcome that would be analogous to the increased vulnerability of old reactivated memory to mild hypothermia. The fact that retrograde amnesia was produced for the final habit when a single warm-up trial preceded ECS after a 3day delay interval (Howard et al., 1974) is consistent with the view that older (reactivated) memories can be more susceptible than new learning.

Earlier we discussed evidence showing that RA decreases as the interval between training and the amnestic agent increases. Is there a temporal gradient of susceptibility to amnesia following reactivation of old memory? Using CS exposure as the reactivation manipulation, Mactutus et al. (1982) showed a timedependent decline in the severity of amnesia with increased delay between reactivation and hypothermia. Whether the gradient for old memory is exactly the same as that for new learning is not yet clear, but there seems little doubt that as reactivation subsides the vulnerability decreases.

The studies by Misanin et al. (1968) and Mactutus et al. $(1979,1982)$ employed exposure to the CS+ as a reactivation treatment. We have recently shown that amnesia for earlier established Pavlovian conditioning can be achieved when exposure to the UCS, rather than the CS, is the source of cuing (Richardson, Riccio, \& Mowrey, 1982). In this paradigm, exposure to a noncontingent footshock (NCFS) functions to increase the vulnerability of an intact memory to amnestic insult. This finding is consistent with those of several earlier studies that used ECS, as well as with the implication of Howard et al. (1974). Furthermore, as in the studies using the CS to reactivate memory, a salient feature of the data was the time-dependent gradient of amnesia: severity of amnesia diminished as a function of the delay between the NCFS (reactivation) and hypothermia (amnestic treatment).

Reactivation studies. More compelling evidence that the target information for amnesic subjects may be "gone, but not forgotten" comes from research on induced recovery from amnesia. Before describing these findings, however, we would call attention to a watershed study by Braun, P. M. Meyer, and D. R. Meyer (1966). The phenomenon they observed radically altered the way the Meyers and their colleagues viewed the effects of brain damage on memory and thus indirectly led to this symposium. Pursuing earlier evidence that amphetamine could restore the placing response in spinal kittens, Braun et al. demonstrated that administration of amphetamine also eliminated the retention loss for a brightness discrimination habit that occurs in posterior decorticate rats. Since the drug did not affect original acquisition of discrimination learning in intact rats, Braun et al. concluded that the savings in relearning in lesioned rats receiving amphetamine reflected a facilitation of retrieval. Clearly, the lesion could not simply have destroyed a memory trace. Braun et al. proposed that amphetamine permitted "access to the engram" (see 'D. R. Meyer, 1972). While this conclusion presaged other studies of induced recovery from retrograde amnesia, its implications may have escaped immediate attention, perhaps in part because of traditionally different emphases between investigations studying surgically induced brain damage and those examining traumatic amnesia with "noninvasive" agents. As this issue testifies, some inroads on these artificial boundaries are being made, although with the "cost" that the relevant literature has become even more enormous!

Unlike spontaneous recovery-which, as we have seen, probably does not occur-several types of manipulations have been demonstrated to reverse the deleterious effects of ECS and other agents on retention. One class of treatment involves the use of some aspect of the training situation, such as the CS. Although exposure to the CS without the UCS is nominally an extinction manipulation, some years ago Silvestri, Rohrbaugh, and Riccio (1970) found that forgetting of conditioned fear in immature rats could be alleviated by periodic reminders in which subjects were returned briefly to the original conditioned cues. This outcome extended the classic reinstatement paradigm of Campbell and Jaynes (1966) in which each reminder treatment was a single CS-UCS re-pairing (an abridged form of the conditioning episode). The outcome in the Silvestri et al. (1970) study indicated that at least under some circumstances the effects of a brief extinction trial could be to improve, rather than diminish, test performance. Using a similar strategy, Gordon and Mowrer (1980) trained rats on a one-way avoidance task and later exposed them to the CS alone prior to testing. For subjects that had received ECS after acquisition, the CS reminder improved performance; for those that had not received ECS, the CS impaired performance. Thus, in the amnestic condition, the enhanced re- 
trieval cues provided by the CS apparently exceeded its other demonstrable function of providing incompatible information (extinction). Although it is not entirely clear why the repeated active avoidance test trials per se would fail to serve as reminders (since CS exposure was included), at the very least these data are not easily interpreted as reacquisition. In examining the effects of several types of reinstatement or "memory jog" on ECS-induced RA for fear conditioning, DeVietti and Hopfer (1974) also showed that exposure to training cues alone was sufficient to produce partial recovery of memory.

Alleviation of RA is also obtained if subjects are reexposed to another component of training, the reinforcer or UCS. A particularly careful and wellcontrolled study using the UCS as a "reminder" is provided by Miller and Springer (1972). Prior to testing, rats made amnestic by ECS were given the UCS (footshock) in an apparatus very different from that used in punishment training. Therefore, the reminder footshock was noncontingent with respect to either the punished response or the stimulus context present at acquisition. Retention in subjects receiving the noncontingent footshock (NCFS) was significantly enhanced and, within the limits of measurement, was comparable to retention controls which had not received ECS after training. Because systemic stress from the shock and ECS might also result in longlatency test performance and might mimic memory recovery, Miller and Springer (1972) included another essential control condition in which subjects received pseudotraining (also a noncontingent footshock) followed by ECS and another NCFS prior to testing. Since this group received the same sequence of footshocks (except for location) and ECS as the recovery group but showed very short latencies at testing, the improved passive avoidance in the reminder condition cannot be attributed to stressinduced performance artifacts. Rather, the induced recovery suggests that, in rats receiving ECS, the memory was stored but unavailable under the usual test conditions. As in the Braun et al. (1966) study with amphetamine, a manipulation prior to testing permitted access to the engram. Presumably, the NCFS reminder treatment facilitated retrieval by providing some of the attributes of the target memory (see Spear, 1973, 1978). If this is the case, then the NCFS "reminder" should be ineffective when the learning is based upon appetitive reinforcement. Evidence of such specificity is available: In a report showing that ECSinduced amnesia for an appetitively rewarded response was alleviated by reexposure to the training reinforcer (noncontingently), Miller, Ott, Berk, and Springer (1974) discuss data indicating no restoration of the appetitive memory with NCFS, despite a number of parametric variations in the manipulations.
The reversal of experimentally induced amnesia by a NCFS "reminder" treatment has been documented with respect to other sources of amnesia as well. For example, Quartermain, McEwen, and Azmitia (1970) used ECS or cycloheximide, a protein synthesis inhibitor, to induce amnesia in rats. The NCFS reminder alleviated forgetting in both cases, although brief reexposure to the training situation (in the form of a test trial) prior to the reminder was a necessary condition. Since the reminder was effective even when administered $4 \mathrm{~h}$ after reexposure to the training context, a "reconditioning" explanation seems implausible. Also, Mactutus, Ferek, and Riccio (1980) reported that NCFS as a reminder was effective in alleviating amnesia induced by either body cooling or body heating. The reversal of hyperthermiainduced retention loss was of particular interest because in other respects the amnesia resulting from hyperthermia appears to be unusually profound (cf. Misanin et al., 1979).

An alternative explanation for the reminder effect holds that the NCFS treatment produces "new learning" (Pavlovian conditioning) to cues in the noncontingent apparatus and that this learning transfers, through generalization, to the test situation. Further, as RA is often incomplete, the generalized fear could summate with the residual fear present in the test apparatus to improve performance (Gold \& King, 1974; Gold, Haycock, Macri, \& McGaugh, 1973). Essentially, this interpretation invokes learning mechanisms and incomplete disruption of storage, rather than facilitated retrieval, to explain recovery. A central difficulty for this view has been the failure by most investigators to obtain any substantial effects on performance of NCFS given to untrained or pseudotrained controls (DeVietti \& Bucy, 1975; Mactutus, Ferek, \& Riccio, 1980; Miller \& Springer, 1973, 1974; Quartermain et al., 1970). Furthermore, although a recent analysis of the forgetting of stimulus attributes suggests a possible, more subtle, form of "generalized learning," which might be applicable to the NCFS reminder (Riccio, Richardson, \& Ebner, 1984), the experiments on recovery of amnestic memories by reexposure to the original fear cues (Gordon \& Mowrer, 1980) and those employing reexposure to the amnestic agent (see below) cannot be interpreted as due to new or generalized learning.

Exogenous hormones and memory recovery. Reminders such as conditioned or unconditioned stimulus presentations appear to function by recreating some of the critical stimulus attributes of the training/ amnestic episode. This suggests that pharmacological manipulations of the internal state might also be effective reminders. Such a strategy was successfully used by Klein (1972) to eliminate the retention loss obtained at intermediate intervals after avoidance 
conditioning, that is, the Kamin effect. In a similar vein, Mactutus, Smith, \& Riccio (1980) attempted to mimic the internal context of training by administering ACTH to rats subjected to hypothermia-induced RA. Exogenous ACTH shortly prior to testing markedly alleviated memory loss; however, there was little change in RA with longer intervals between hormone injection and testing. These results suggest, as might be expected, that as the internal cues subside following ACTH administration, the facilitation of retrieval declines. This time-dependent effect of ACTH was also consistent with earlier findings from an extensive parametric study of the reversal of an ECSinduced amnesia by a fragment of the ACTH peptide (Rigter, Elbertse, \& Van Riezen, 1975). In this latter study, the results presumably reflect a direct effect of ACTH on the CNS, as these hormone fragments are virtually devoid of the classic corticosteroid-releasing activity of $\mathrm{ACTH}_{1-39}$. Since the peripheral state elicited by $\mathrm{ACTH}_{1-39}$ must ultimately be "interpreted" and mediated through central mechanisms in order to affect performance, one might speculate that the peptide fragments such as $\mathrm{ACTH}_{4-10}$ produce this central "context"' more directly.

The contribution of hormonal state prior to testing in reversing amnesia has also been shown in a recent study by Concannon and Carr (1982). These investigators used diethyldithiocarbamic acid (DDC) as the amnestic agent, a treatment known to produce robust RA. Since earlier work had indicated that DDCinduced amnesia could be modulated by posttraining manipulation of catecholamine levels (e.g., Martinez, Jensen, \& McGaugh, 1981), the importance of the Concannon and Carr study lay in its obtaining attenuation of RA with exogenous epinephrine administration prior to testing (cf. Quinton \& Bloom, 1977). This outcome seems specifically to implicate retrieval mechanisms, whereas the modulation by pre- and posttraining pharmacological treatments could be based upon storage processes.

\section{Reversal of Amnesia: Reexposure to the Amnestic Agent}

A recovery manipulation that we have found particularly convincing and of theoretical value involves reexposure to the amnestic agent. An early study by Thompson and Neely (1970) showed that ECSinduced amnesia was alleviated if subjects were given ECS again shortly prior to testing. A comparable type of study was first conducted in our lab by Hinderliter et al. (1975). A recooling exposure prior to testing dramatically reduced the severity of RA in rats rendered amnestic by posttrial administration of hypothermia. The importance of controls for systemic stress is quite obvious under these conditions, so it is important to note that induction of hypothermia prior to testing had virtually no effect on test performance of either untrained rats or rats that earlier had received NCFS (in place of training) followed by hypothermia.

The reversal of amnesia by reexposure to the amnestic treatment appears paradoxical. If the initial insult destroys a portion of the engram, how can a second insult reverse this process? An approach that focuses on the congruence of encoding and retrieval environments may help to resolve the apparent dilemma. Hinderliter et al. (1975) suggested that hypothermia becomes a contextual cue that, like more traditional contexts, is necessary for subsequent memory retrieval (cf. Spear, 1978). In contrast with the usual environmental contexts, however, the hypothermia is not present until after the nominal "learning" event. Presumably, then, some posttrial representation becomes linked with the hypothermic state. This model is similar to a storage view in assuming continued posttrial processing of information, but attributes the memory failure to the lack of contextual cues for retrieval rather than disruption of consolidation. Because our interpretation shares some similarities to the episodes sometimes described in mystery novels in which the witness to a crime is rendered amnesic by a blow to the head only to regain his/her memory at some critical moment following a second, inadvertent, concussive event, it becomes clear why several colleagues affectionately refer to this as the "two-bump" theory.

One other aspect of the Hinderliter study might be mentioned. Subjects that had not received retrograde treatment but were given hypothermia prior to testing showed no disruption of retention. Apparently, superimposing a potent, but irrelevant, stimulus context does little to impair retrieval, but presentation of a context relevant to encoding is highly important for access to memory. This pattern of results appears formally similar to the asymmetrical state-dependent disassociation often seen with drugs, although the drug studies of retention typically are based on an anterograde paradigm.

The reversibility of hypothermia-induced RA was further established in several studies examining in greater detail the role of body temperature as a "context" at testing. For example, Mactutus and Riccio (1978) obtained alleviation of memory loss when recooled subjects were tested at $30^{\circ} \mathrm{C}$ (rectal temperature) but not when they were tested at a slightly warmer body temperature $\left(34^{\circ} \mathrm{C}\right)$. Moreover, amnesia was reversible 7 days after training/treatment as well as 1 day later, although perhaps less completely in the former case. [Incidentally, this evidence of temperature dependence in the recovery of memory contrasts with the relationship found in the delayed onset of amnesia, when memory loss does not develop until well after body temperatures have returned to near normal levels (Mactutus \& Riccio, 1978).]

Because rats in the Mactutus and Riccio study were 
allowed to rewarm spontaneously to the temperatures at which they were tested, the design was essentially correlational in nature. In order to achieve a more experimental analysis, a subsequent study (Mactutus, McCutcheon, \& Riccio, 1980) took advantage of the ease with which body temperature can be manipulated. As in the previous study, amnestic rats were recooled prior to testing, but some were then artificially rewarmed for different durations. When the rewarming exposure in rats was sufficient to return body temperatures to $35^{\circ}-36^{\circ} \mathrm{C}$, amnesia was still obtained. On the other hand, recooled groups with either very brief or no rewarming exposure showed substantial memory recovery. Since all groups were tested $2 \mathrm{~h}$ after recooling, the differential alleviation of amnesia seems specific to body temperature and/or concomitant internal stimulus states.

Another experiment in the Mactutus, McCutcheon, \& Riccio (1980) study used a within-subjects design to demonstrate the "waxing and waning" of amnesia in accordance with temperature-related cues. Rats received three daily tests following hypothermiainduced amnesia. Recooling alone preceded the first and third tests, whereas recooling followed by rapid rewarming preceded the second test. Although the repeated test procedure introduces some complications, subjects generally displayed strong retention, amnesia, and retention again over the respective test days. Thus, despite the fact that rewarming "cancelled" memory recovery on the second test, it was still possible to reverse the amnesia on the following day.

A recent study of recovery from experimentally induced anterograde amnesia provides a particularly compelling example of the critical relationship between the status of cues at testing and the success of memory retrieval (Richardson, Guanowsky, Ahlers, \& Riccio, 1984). Since the anterograde paradigm the amnestic treatment precedes training, rats received a punishment training trial while in a mildly hypothermic state $\left(29^{\circ} \mathrm{C}\right)$. Although this arrangement can introduce methodological complications, short-term testing indicated that acquisition was intact, thus ruling out sensory or associative deficits at encoding (see Richardson, Riccio, \& Morilak, 1983). However, under these conditions, retention loss sets in very rapidly after training and full blown amnesia can be seen within several hours. As in the retrograde studies, the anterograde amnesia was alleviated when the animals were recooled prior to testing. Of particular relevance, the recovery of memory was an inverse function of body temperature at the time of testing. Animals recooled and tested at $29^{\circ} \mathrm{C}$ (training temperature) displayed strong memory recovery, whereas subjects allowed to rewarm to $33^{\circ} \mathrm{C}$ did not. Retention performance was intermediate at $31^{\circ} \mathrm{C}$. This thermal gradient of induced recovery is very reminiscent of the performance changes seen in tests of stimulus generalization, and further supports the contention that realigning the stimulus context at testing to something closer to that present at training can have a profoundly beneficial effect on memory retrieval. Furthermore, by demonstrating the reversibility of anterograde amnesia, these data also extend the generality of the thesis that in many cases of amnesia memory may be "gone, but not forgotten."

As noted before, an earlier established memory is susceptible to an amnestic treatment if that memory is "reactivated" shortly prior to that treatment. Furthermore, it appears that an old reactivated memory is susceptible to treatments (i.e., mild hypothermia) that are ineffective in producing amnesia for a new memory. But can the amnesia for old memory be reversed? To our knowldege, the only data pertinent to this question were reported by Mactutus et al. (1982, Experiment 6). Previously trained rats were tested $24 \mathrm{~h}$ after receiving cue exposure (reactivation) and either deep or mild hypothermia. Prior to test, some subjects were reexposed to hypothermia. Regardless of the intensity of the amnestic treatment, the subjects tested while moderately hypothermic (about $30^{\circ} \mathrm{C}$ ) showed significantly better retention than the nonrecooled controls. Thus, this experiment demonstrates not only amnesia for old reactivated memories but also the reversibility of such amnesia.

In our view, the temporal gradient of susceptibility to RA following reactivation and the recovery of old memory from amnesia may best be seen as examples that reactivated information can become reencoded in terms of the current context of the organism. More specifically, cue exposure leads to retrieval of the target memory and some proportion of the now active attributes become associated with the hypothermic state. As with new learning, the longer the delay of treatment, the less likely it is that the representation of training will be linked to the altered state, and therefore the weaker the amnesia. But with conditions in which amnesia is induced, later recooling establishes again the thermal and/or related cues of the internal milieu that permit retrieval of memory; that is, amnesia is reversed.

The substantial evidence for induced recovery from amnesia makes it clear that the electrophysiological consequences of amnestic treatments (CNS seizures) cannot be distrupting the neural substrates of storage of information. We think these findings dovetail nicely with the conclusions drawn from studies of brain lesions and retention: extensive destruction of cortical tissue disrupts memory retrieval but does not abolish the memory trace (e.g., LeVere, 1984; Meyer, 1984).

The recovery from amnesia is consistent with the view that memory losses are often the result of retrieval failure-an interpretation applied to the phenomenon of retrograde amnesia in various inno- 
vative studies (described above) by Lewis, Miller, and Misanin, among others, and persuasively presented as a general model of forgetting by Spear (1973, $1978,1981)$. Unfortunately, the term "retrieval deficit" with respect to amnesia seems to have engendered considerable confusion as well as argument. The primary objections seem to center around these questions: How can a deficit in retrieval account for the temporal gradient of amnesia? If the retrieval system is impaired, how can recovery be induced? We suggest that it makes little sense to speak of retrieval deficits per se, as if a mechanism were broken. To our way of thinking, it is more appropriate to conceptualize the deficit as referring to a lack of correspondence between the situations present at encoding and at testing (retrieval). Perhaps the expression should really be "encoding-retrieval incongruity," since, as Schachter and Tulving (1982) have pointed out, a core notion in memory models is the "interactive relationship" between encoding and retrieval processes. From this perspective, the recovery from amnesia achieved by reexposure to the amnestic treatment is readily understood. The training episode, by virtue of continued postacquisition processes, becomes associated with, or "embedded in," the amnestic (hypothermic) state. When testing occurs a day or two later under the usual normothermic conditions, the absence of important internal contextual cues impairs retrieval of memory. This mismatch of conditions constitutes the "retrieval" deficit. Conversely, amnesia is reversed or attenuated in subjects recooled and tested while hypothermic because at least a portion of the conditions around the time of encoding have been reestablished. Degrading those contextual cues, either by spontaneous or artificial rewarming, would prevent or reduce recovery, an outcome that is obtained, as we have noted earlier.

Furthermore, an interpretation of amnesia in terms of the interactive nature of encoding and retrieval makes it understandable why the severity of amnesia is characteristically time-dependent. At longer training-treatment delays, less of the encoding coincides with the amnestic state. Thus, there is less disparity between encoding and test situations and greater probability that the cues at testing will be appropriate for retrieval. An interesting and seemingly counterintuitive implication of this model is that the induced recovery should be strongest when amnesia is most severe. In contrast, if memory recovery depends upon the summation of residual memory with new learning, as a consolidation view contends, then better recovery should be obtained when amnesia is only partial (that is, when there is already substantial residual memory). Taking advantage of the gradient of amnesia produced by delay of treatment, Riccio, Mactutus, Hinderliter, and McCutcheon (1979) examined the effectiveness of pretest recooling on am- nesia of varying strengths. Although the baseline delay gradient resulting from $0.5-, 5-$, and $10-\mathrm{min}$ intervals proved to be unexpectedly shallow, recooling produced a larger and statistically significant enhancement of test latencies in the short-delay condition and a much smaller and nonsignificant increase in latencies in the long-delay group. (Because a similar pattern could be artificially produced by ceiling effects, care was taken to insure that the recovery scores not be constrained by the arbitrary trial cutoff point.) This inverse relationship between severity of amnesia and the effectiveness of a reactivation treatment is consistent with results reported earlier in an important study by DeVietti and Bucy (1975). These investigators varied the strength of ECSinduced amnesia in a lick-suppression paradigm by manipulating the interval between the training/ECS administration and the subsequent reminder episode, a weak noncontingent footshock. The reminder treatment produced memory recovery under the strong, but not the mild, amnesia condition. Taken together, these findings add rather convincing support for the contention that even severe amnesia need not represent the destruction or impairment of storage. In addition, they further illustrate how memory can be modulated by the degree of correspondence between the encoding and retrieval environments.

\section{Some New Directions}

As the preceding review indicates, many studies have demonstrated the recovery of memory from amnesia, but two very important issues related to this finding have been largely unexplored. The first issue concerns the permanence of a recovered memory, and the second concerns what we shall tentatively call the "content"' of the recovered amnestic memory.

With respect to permanence or durability of recovery, we have already noted that in many cases pretest treatment yields a relatively transient alleviation of amnesia. Reexposure to the amnestic treatment or administration of stress-related hormones produces recovery that lasts only hours at best. Although these findings support the view that retrieval is contingent upon the contemporary contextual state, they do not exclude the possibility of a more persistent recovery, perhaps through transfer of control over responding to other environmental stimuli. A study by Mactutus, Smith, and Riccio (1980) illustrates this approach. Amnestic rats received an ACTH injection prior to a brief reexposure to the original fear cues and then were tested after various retention intervals. The "re-pairing" produced attenuation of amnesia for 7 days, a much longer recovery than that produced by ACTH alone (see also Haroutunian \& Riccio, 1977, for a related finding on reinstatement of memory in immature rats). It remains to be determined whether reexposure to the amnestic treatment can function similarly. Further- 
more, the specific constellation of training stimuli and exposure durations needed for optimizing recovery remain unexplored, although a study being initiated by J. H. Steele and R. Richardson is intended to address some of these issues.

Even with the types of reminder (e.g., NCFS) that appear to produce a direct and persistent recovery from amnesia, the durability of the effect has not been fully determined. For example, Miller and Springer (1972) found that ECS-induced RA was alleviated by an NCFS reminder for at least 5 days (the longest reminder-test interval employed). But, given the very long intervals over which passive avoidance is typically retained by controls, it is not yet clear that the induced recovery would share the same degree of durability.

As these considerations also suggest, determination of the characteristics that distinguish treatments producing transient recovery of memory from those producing more durable recovery is of practical and theoretical importance. Might the difference be in whether reminder treatments reinstate the attributes of the training context, as opposed to those of the amnestic episode? Or are more mundane parametric variables responsible for the differential persistence in recovery?

A second important issue with regard to recovered memories that has received virtually no attention is the "content," or nature of the representation, of these recovered memories. An underlying assumption in research on alleviation of amnesia is that the memory at recovery has essentially the same characteristics as it had at encoding. That is, if an amnestic treatment does not alter the memory itself but only its accessibility, then treatments that alleviate amnesia allow access to the earlier encoded memory. If this interpretation of the amnestic syndrome is correct, then the "content" of a recovered memory should be the same as that of a retention control condition.

But how can it be determined if two memories (one "normal" and one "recovered") contain the same information? One approach is to examine the stimulus attributes constituting the respective memories. Spear (1973, 1978) and Underwood (1969), among others, have suggested that memory be conceptualized as having multiple attributes. Included among the attributes of memory are the background environmental cues (i.e., external contextual cues) present at the time of training. Although these contextual cues are irrelevant to the reinforcement contingencies, there is abundant evidence showing that they are encoded as an attribute of the original memory. For instance, Gordon (1981) and others (e.g., Richardson, Riccio, Guanowsky, \& Okonkwo, 1983) have shown that changing the context between training and testing produces a marked performance decrement, and this outcome has been interpreted as reflecting a retrieval failure (cf. Spear, 1978). That is, the similarity of cues present at training and testing is not sufficient to permit retrieval of the target information in those subjects tested in a context different from that in which they were trained. Thus, it would seem appropriate to determine if contextual cues play a similar role in retrieval of recovered amnestic memories.

This contextual-shift paradigm is the strategy being followed by the second author in some recently initiated research. More specifically, amnestic rats will be reexposed to the amnestic treatment to induce recovery, and then tested in either the original training environment or a new context. If contextual cues are a component of recovered memory, then the altered context at testing should disrupt retention, as it does in controls. Conversely, if test performance is invariant across contexts, then a recovered memory will have been shown to differ from the nonamnestic engram in at least one important way. A similar strategy will be used to investigate the content of other representations such as the training CS (cf. D. R. Thomas, 1981; D. A. Thomas \& Riccio, 1979). Whether the nature of recovered memories proves to be similar to or different from "normal" memories, we think this line of inquiry will provide useful information in characterizing engrams that are "gone, but not forgotten."

\section{REFERENCES}

Aвт, J. P., Essman, W. B., \& Jarvik, M. E. (1961). Etherinduced retrograde amnesia for one-trial conditioning in mice. Science, 133, 1477-1478.

Banker, G., Hunt, E., \& Pagano, R. (1969). Evidence supporting the memory disruption hypothesis of electroconvulsive shock action. Physiology \& Behavior, 4, 895-899.

Beitel, R. E., \& Porter, P. B. (1968). Deficits in short- and long-term retention and impairments in learning induced by severe hypothermia in mice. Journal of Comparative and Physiological Psychology, 66, 53-59.

Braun, J. J., Meyer, P. M., \& Meyer, D. R. (1966). Sparing of a brightness habit in rats following visual decortication. Journal of Comparative and Physiological Psychology, 61, 79-82.

Campbell, B. A., \& JAYnes, J. (1966). Reinstatement. Psychological Review, 73, 478-480.

Carlton, P. L., \& Vogel, J. R. (1967). Habituation and conditioning. Journal of Comparative and Physiological Psychology, 63, 348-351.

Channell, S., \& Hall, G. (1983). Contextual effects in latent inhibition with an appetitive conditioning procedure. Animal Learning \& Behavior, 11, 67-74.

Che rkin, A. (1969). Kinetics of memory consolidation: Role of amnesic treatment parameters. Proceedings of the National Academy of Sciences, 63, 1094-1101.

Concannon, J. T., \& Carr, M. (1982). Pre-test epinephrine injections reverse DDC-induced retrograde amnesia. Physiology \& Behavior, 9, 443-448.

David-Remacle, M. (1973). Attenuation of anoxia-induced retrograde amnesia in rats by a pretraining placebo injection. Physiology \& Behavior, 10, 693-696.

DeVietti, T. L., \& Bucy, C. E. (1975). Recovery of memory after reminder: Evidence for two forms of retrieval deficit induced by ECS. Physiological Psychology, 3, 19-25.

DeVIETTI, T. L., \& Holliday, J. H. (1972). Retrograde amnesia 
produced by ECS after reactivation of a consolidated memory trace: A replication. Psychonomic Science, 29, 137-138.

DeVietti, T. L., \& Hopfer, T. M. (1974). Reinstatement of memory in rats: Dependence upon two forms of retrieval deficit following electroconvulsive shock. Journal of Comparative and Physiological Psychology, 86, 1090-1099.

Duncan, C. P. (1949). The retroactive effect of electroshock on learning. Journal of Comparative and Physiological Psychology, 42, 32-44.

Gelle r, A., \& JARvik, M. E. (1968). The time relations of ECS induced amnesia. Psychonomic Science, 12, 169-170.

Gerson, R., \& Hendersen, R. W. (1978). Conditions that potentiate the effects of electroconvulsive shock administered 24 hours after avoidance training. Animal Learning \& Behavior, 6, 346-351

Glickman, S. E. (1961). Perseverative neural processes and consolidation of the memory trace. Psychological Bulletin, 58, 218-233.

Gold, P. E., Haycock, J. W., Macri, J., \& McGaugh, J. L. (1973). Retrograde amnesia and the "reminder effect": An alternative interpretation. Science, 180, 1199-1200.

Gold, P. E., \& KInG, R. A. (1972). Amnesia: Tests of the effect of delayed footshock-electroconvulsive shock pairings. Physiology \& Behavior, 8, 797-800.

Gold, P. E., \& KING, R. A. (1974). Retrograde amnesia: Storage failure versus retrieval failure. Psychological Review, 81, 465-469.

Gondon, W. C. (1981). Mechanisms for cue-induced retention enhancement. In N. E. Spear \& R. R. Miller (Eds.), Information processing in animals: Memory mechanisms. Hillsdale, NJ: Erlbaum.

Gordon, W. C., \& Mowrer, R. R. (1980). The use of an extinction trial as a reminder treatment following ECS. Animal Learning \& Behavior, 8, 363-367.

HALl, G. (1980). Exposure learning in animals. Psychological Bulletin, 88, 535-550.

Haroutunian, V., \& Riccio, D. C. (1977). Effect of arousal conditions during reinstatement treatment upon learned fear in young rats. Developmental Psychobiology, 10, 25-32.

HEBB, D. O. (1949). The organization of behavior. New York: Wiley.

Herz, M. J., \& Peeke, H. V. S. (1967). Permanence of retrograde amnesia produced by electroconvulsive shock. Science, 156, 1396-1397.

Herz, M. J., \& PEeke, H. V. S. (1968). ECS-produced retrograde amnesia: Permanence versus recovery over repeated testing. Physiology \& Behavior, 3, 517-521.

Hinderlite R, C. F. (1978). Hypothermia: Amnestic agent, punisher, and conditions sufficient to attenuate amnesia. Physiological Psychology, 6, 23-28.

Hinderliter, C. F., \& Riccio, D. C. (1977). Long-term effects of prior experience in attenuating amnesia. American Journal of Psychology, 90, 407-418.

Hinderliter, C. F., Smith, S. L., \& Misanin, J. R. (1973). Effects of pretraining experience on retention of a passive avoidance task following ECS. Physiology \& Behavior, 10, 671-675.

Hinderliter, C. F., Webster, T., \& Riccio, D. C. (1975). Amnesia induced by hypothermia as a function of treatmenttest interval and recooling in rats. Animal Learning \& Behavior, 3, 257-263.

Howard, R. L., Glendenning, R. L., \& Meyer, D. R. (1974). Motivational control of retrograde amnesia: Further explorations and effects. Journal of Comparative and Physiological Psychology, 86, 187-192.

HowARD, R. L., \& MEYER, D. R. (1971). Motivational control of retrograde amnesia in rats: A replication and extension. Journal of Comparative and Physiological Psychology, 74, 37-40.

JENSEN, R. A., \& Riccio, D. C. (1970). Effects of a prior experience upon retrograde amnesia induced by hypothermia. Physiology \& Behavior, 5, 1291-1294.
Jensen, R. A., Riccio, D. C., \& Gehres, L. (1975). Effects of prior aversive experience upon retrograde amnesia induced by hypothermia. Physiology \& Behavior, 15, 165-169.

Kasprow, W. J., Cacheiro, H., Balaz, M. A., \& Miller, R. R. (1982). Reminder-induced recovery of associations to an overshadowed stimulus. Learning and Motivation, 13, 155-166.

Kasprow, W. J., Schachtman, T. R., Balaz, M. A., \& Miller, R. R. (1983). Attenuation of experimental retrograde amnesia through pretraining administration of a dissimilar amnestic agent. Physiology \& Behavior, 30, 193-196.

KESNE R, R. P., \& Doty, R. W. (1968). Amnesia produced in cats by local seizure activity initiated from the amygdala. Experimental Neurology, 21, 58-68.

Kesner, R. P., McDonough, J. H., \& Doty, R. W. (1970). Diminished amnestic effects of a second electroconvulsive seizure. Experimental Neurology, 27, 527-533.

KIng, R. A., \& Glasser, R. L. (1970). Duration of electroconvulsive shock-induced retrograde amnesia in rats. Physiology \& Behavior, 5, 335-340.

KLE IN, S. B. (1972). Adrenal-pituitary influence in reactivation of avoidance-learning memory in the rat after intermediate intervals. Journal of Comparative and Physiological Psychology, 79, 341-359.

LEVERE, T. E. Recoveries of function after brain damage: Variables influencing retrieval of latent memories. Physiological Psychology, 12, 73-80.

LEwIs, D. J. (1979). Psychobiology of active and inactive memory. Psychological Bulletin, 86, 1054-1083.

Lewis, D. J., Miller, R. R., \& Misanin, J. R. (1968). Control of retrograde amnesia. Journal of Comparative and Physiological Psychology, 66, 48-52.

Lubow, R. E., \& Moore, A. U. (1959). Latent inhibition: The effect of nonreinforced pre-exposure to the conditioned stimulus. Journal of Comparative and Physiological Psychology, 52, 415-419.

Luttges, M. W., \& McGaugh, J. L. (1967). Permanence of retrograde amnesia produced by electroconvulsive shock. Science, 156, 408-410.

LYNCH, S., \& Y ARNELL, P. R. (1973). Retrograde amnesia and delayed forgetting after concussion. American Journal of Psychology, 86, 643-645.

Mactutus, C. F., Ferek, J. M., George, C. A., \& Riccio, D. C. (1982). Hypothermia-induced amnesia for newly acquired and old reactivated memories: Commonalities and distinctions. Physiological Psychology, 10, 79-95.

Mactutus, C. F., Ferek, J. M., \& Riccio, D. C. (1980). Amnesia induced by hyperthermia: An unusually profound, yet reversible memory loss. Behavioral and Neural Biology, 30, 260-277.

Mactutus, C. F., McCutcheon, K., \& Riccio, D. C. (1980). Body temperature cues as contextual stimuli: Modulation of hypothermia-induced retrograde amnesia. Physiology \& Behavior, 25, 875-883.

Mactutus, C. F., \& Riccio, D. C. (1978). Hypothermia-induced retrograde amnesia: Role of body temperature in memory retrieval. Physiological Psychology, 6, 18-22.

Mactutus, C. F., Riccio, D. C., \& FeneK, J. M. (1979). Retrograde amnesia for old (reactivated) memory: Some anomalous characteristics. Science, 204, 1319-1320.

Mactutus, C. F., Smith, R. L., \& Riccio, D. C. (1980). Extending the duration of ACTH-induced memory reactivation in an amnesic paradigm. Physiology \& Behavior, 24, 541-546.

Madsen, M. C., \& McGaugh, J. L. (1961). The effect of ECS on one-trial avoidance learning. Journal of Comparative and Physiological Psychology, 54, 522-523.

Maki, W. S., \& Hegvik, D. K. (1980). Directed forgetting in pigeons. Animal Learning \& Behavior, 8, 567-574.

Martinez, J. L., Jensen, R. A., \& McGaugh, J. L. (1981). Attenuation of experimentally-induced amnesia. Progress in Neurobiology, 16, 155-186. 
McDonough, J. H., JR., \& Kesner, R. P. (1971). Amnesia produced by brief electrical stimulation of amygdala or dorsal hippocampus in cats. Journal of Comparative and Physiological Psychology, 77, 171-178.

McGaugh, J. L. (1966). Time-dependent processes in memory storage. Science, 153, 1351-1358.

McGaugh, J. L., \& Dawson, R. G. (1971). Modification of memory storage processes. In W. K. Honig \& P. H. R. James (Eds.), Animal memory. New York: Academic Press.

McGaugh, J. L., \& Landfield, P. W. (1970). Delayed development of amnesia following ECS. Physiology \& Behavior, 5, 1109-1113.

Meyer, D. R. (1972). Access to engrams. American Psychologist, 27, 124-133.

MEYER, D. R. (1984). The cerebral cortex: Its roles in memory storage and remembering. Physiological Psychology, 12, 81-88.

Mille R, R. R. (1970). Effects of environmental complexity on amnesia induced by electroconvulsive shock in rats. Journal of Comparative and Physiological Psychology, 71, 267-275.

Miller, R. R., OtT, C. A., Berk, A. M., \& Springer, A. D. (1974). Appetitive memory restoration after electroconvulsive shock in the rat. Journal of Comparative and Physiological Psychology, 87, 717-723.

Miller, R. R., \& Springer, A. D. (1971). Temporal course of amnesia in rats after electroconvulsive shock. Physiololgy \& Behavior, 6, 229-234.

Miller, R. R., \& SPringer, A. D. (1972). Induced recovery of memory in rats following electroconvulsive shock. Physiology \& Behavior, 8, 645-651.

Miller, R. R., \& Springer, A. D. (1973). Amnesia, consolidation and retrieval. Psychological Review, 80, 69-79.

Miller, R. R., \& Springer, A. D. (1974). Implications of recovery from experimental amnesia. Psychological Review, 81, 470-473.

Misanin, J. R., Mille R, R. R., \& Lewis, D. (1968). Retrograde amnesia produced by electroconvulsive shock after reactivation of a consolidated memory trace. Science, 160, 554-555.

Misanin, J. R., Vonheyn, R. E., Bartelt, S. W., Boulden, W. L., \& Hinderliter, C. F. (1979). The effect of hyperthermia on memory in rats. Physiological Psychology, 7, 339-344.

Mowren, O. H. (1960). Learning theory and behavior. New York: Wiley.

NACHMAN, M., \& MEinecke, R. O. (1969). Lack of retrograde amnesia effects of repeated electroconvulsive shock and carbon dioxide treatments. Journal of Comparative and Physiological Psychology, 68, 631-636.

Palfai, T., \& Chillag, D. (1971). Time-dependent memory deficits produced by pentylenetetrazol (metrazol): The effects of reinforcement magnitude. Physiology \& Behavior, 7, 439-442.

Paolino, R. M., Quartermain, D., \& Miller, N. E. (1966). Different temporal gradients of retrograde amnesia produced by carbon dioxide anesthesia and electroconvulsive shock. Journal of Comparative and Physiological Psychology, 62, 270-274.

Pringst, B. E., \& King, R. A. (1969). Effects of post training electroconvulsive shock on retention-test performance involving choice. Journal of Comparative and Physiological Psychology, 68, 645-649.

Quartermain, D., McEwen, B. S., \& Azmitia, E. C. (1970). Amnesia produced by electroconvulsive shock or cycloheximide: Conditions for recovery. Science, 169, 683-686.

Quinton, E. E., \& BLoom, A. S. (1977). Effects of d-amphetamine and strychnine on cycloheximide and diethyldithiocarbamate induced amnesia in rats. Journal of Comparative and Physiological Psychology, 91, 1390-1397.

REISS, S., \& WAGNer, A. R. (1972). CS habituation produces a "latent inhibition effect" but no active "conditioned inhibition." Learning and Motivation, 3, 237-245.

Rıвот, T. A. (1883). The diseases of memory (J. Fitzgerald, Trans.). New York: Humboldt Library (No. 46).
RICcio, D. C. (1975, May). The paradox of retrograde amnesia. Paper presented at the meetings of the Midwestern Psychological Association, Chicago.

Riccio, D. C., Gaebelein, C., \& Cohen, P. (1968). Some behavioral aspects of retrograde amnesia produced by hypothermia. Physiology \& Behavior, 3, 973-976.

Riccio, D. C., Hodges, L. A., \& Randall, P. K. (1968). Retrograde amnesia produced by hypothermia in rats. Journal of Comparative and Physiological Psychology, 66, 618-622.

Riccio, D. C., Mactutus, C. F., Hinderliter, C. F., \& McCutcheon, K. (1979). Severity of amnesia and the effectiveness of reactivation treatment: Evidence for a retrieval process. Physiological Psychology, 7, 59-63.

Riccio, D. C., Richardson, R., \& Ebner, D. L. (1984). Memory retrieval deficits based upon altered contextual cues: A paradox. Psychological Bulletin, 96, 152-155.

Riccio, D. C., \& Stikes, E. R. (1969). Persistent but modifiable retrograde amnesia produced by hypothermia. Physiology \& Behavior, 4, 649-652.

Richardson, R., Guanowsky, V., Ahlers, S. T., \& Riccio, D. C. (1984). Role of body temperature in the onset of, and recovery from, hypothermia-induced anterograde amnesia. Physiological Psychology, 12, 125-132.

Richardson, R., Riccio, D. C., Guanowsky, V., \& OKonkwo, A. E. (1983, May). Disruptive effects of context shifts diminish as a function of retention interval. Paper presented at the Midwestern Psychological Association, Chicago.

Richardson, R., Riccio, D. C., Jamis, M., Skozcen, T., \& Cabosky, J. (1982). Modification of reactivated memory through "counterconditioning." American Journal of Psychology, 95, 67-84.

Richardson, R., Riccio, D. C., \& Molenda, S. (1982). Reducing vulnerability to retrograde amnesia treatments: Can new memory be deactivated? Physiology \& Behavior, 29, 1117-1123.

Richardson, R., Riccio, D. C., \& Morilak, D. (1983). Anterograde memory loss induced by hypothermia in rats. Behavioral and Neural Biology, 37, 76-88.

Richardson, R., Riccio, D. C., \& Mowrey, H. (1982). Retrograde amnesia for previously acquired Pavlovian conditioning: UCS exposure as a reactivation treatment. Physiological Psychology, 10, 384-390.

Rigter, H., Elbertse, R., \& van Riezen, H. (1975). Timedependent anti-amnestic effect of $\mathrm{ACTH}_{4-10}$ and desglycinamidelysine vasopressin. In W. H. Gispen, T. B. van Wimersma Greidanus, B. Bohus, \& D. de Wied (Eds.), Progress in brain research: Hormones, homeostatis and the brain (Vol. 42, pp. 163-171). Amsterdam: Elsevier.

Robins, M. J., \& MEYer, D. (1970). Motivational control of retrograde amnesia. Journal of Experimental Psychology, 84, 220-225.

Schacter, D. L., \& Tulving, E. (1982). Amnesia and memory research. In L. S. Cermak (Ed.), Human memory and amnesia (pp. 1-32). Hillsdale, NJ: Erlbaum.

Schneider, A. M., \& Sherman, W. (1968). Amnesia: A function of the temporal relation of footshock to electroconvulsive shock. Science, 159, 219-221.

Silvestri, R., Rohrbaugh, M., \& Riccio, D. C. (1970). Conditions influencing the retention of learned fear in young rats. Developmental Psychology, 2, 389-395.

Spear, N. E. (1973). Retrieval of memory in animals. Psychological Review, 80, 163-194.

SPEAR, N. E. (1978). The processing of memories: Forgetting and retention. Hillsdale, $\mathrm{NJ}$ : Erlbaum.

Spear, N. E. (1981). Extending the domain of memory retrieval. In N. E. Spear \& R. R. Miller (Eds.), Information processing in animals: Memory mechanisms. Hillsdale, NJ: Eribaum.

Stonebraker, T. B., \& Rilling, M. (1981). Control of delayed matching-to-sample performance using directed forgetting techniques. Animal Learning \& Behavior, 9, 196-201.

Thomas, D. A., \& Riccio, D. C. (1979). Forgetting of a CS at- 
tribute in a conditioned suppression paradigm. Animal Learning \& Behavior, 7, 191-195.

Thomas, D. R. (1981). Studies of long-term memory in the pigeon. In N. E. Spear \& R. R. Miller (Eds.), Information processing in animals: Memory mechanisms. Hillsdale, $\mathrm{NJ}$ : Erlbaum.

Thompson, C. I., \& NeELY, J. E. (1970). Dissociated learning in rats produced by electroconvulsive shock. Physiology \& Behavior, 5, 783-786.

Tulving, E., \& Pearlstone, Z. (1966). Availability versus accessibility of information in memory for words. Journal of Verbal Learning and Verbal Behavior, 5, 381-391.

Tulving, E., \& Psotka, J. (1971). Retrograde inhibition in free recall: Inaccessibility of information available in memory store. Journal of Experimental Psychology, 87, 1-8.

Unberwoon, B. J. (1969). Attributes of memory. Psychological Review, 76, 559-573.

Vardaris, R. M., Gaebelein, C., \& Riccio, D. C. (1973).
Retrograde amnesia from hypothermia-induced brain seizures. Physiological Psychology, 1, 204-208.

WAGNER, A. R. (1978). Expectancies and the priming of STM. In S. H. Hulse, H. Fowler, \& W. K. Honig (Eds.), Cognitive processes in animal behavior. Hillsdale, NJ: Erlbaum.

Wagner, A. R., Rudy, J. W., \& Whitlow, J. W., JR. (1973). Rehearsal in animal conditioning. Journal of Experimental Psy. chology Monograph, 97, 407-426.

Zinkin, S., \& Miller, A. J. (1967). Recovery of memory after amnesia induced by electroconvulsive shock. Science, 155, 102-104.

Zonnetzer, S. F., \& McGaugh, J. L. (1971). Retrograde amnesia and brain seizures in mice. Physiology \& Behavior, 7 , 401-408.

(Manuscript accepted for publication June 5, 1984.) 